\title{
A SYNTHESISED REPORT ON THE IMPACT OF THE CORONAVIRUS DISEASE (COVID-19) PANDEMIC ON GIVIL SOCIETY organisations IN WEST AFRICA
}

Research commissioned by the

West Africa Civil Society Institute (WACSI) with support from Wilde Ganzen Foundation 


\section{Researcher:}

Emmanuel Kumi, PhD

\section{Editorial Team}

Nana Afadzinu

Nancy Kankam Kusi

Charles Vandyck

Shu Mabel Lum

Jimm Chick Fomunjong

\section{Designed by:}

Copyright WACSI 2020

All rights reserved. No part of this publication may be used or reproduced in any manner without written permission of the Institute except in the case of brief quotations embodied in critical articles and reviews.

Disclaimer: The author remains responsible for any errors and omission in this report.

\section{For more information, write to:}

West Africa Civil Society Institute (WACSI)

P. O. Box AT1956 Achimota

Accra, Ghana

Email: info@wacsi.org

Tel: (+233) 303937264

Cite as: WACSI (2020). Synthesised Report on the Impact of the Coronavirus Disease (COVID-19) Pandemic on Civil Society Organisations in West Africa, Accra, Ghana. 


\section{West Africa Civil Society Institute}

The West Africa Civil Society Institute (WACSI) was set up by the Open Society Initiative for West Africa (OSIWA) in 2005 to strengthen the institutional and operational capacities of civil society in West Africa based on critical needs assessments and consultations with key civil society constituents and policymakers.

WACSI's institutional strengthening approach has evolved and integrates the varying experiences of working with civil society organisations (CSOs) and development agencies. It is designed to assist organisations and institutions in engaging in assessments, reflection, and improvement, which is aimed at enhancing performance and the achievement of set targets. www.wacsi.org

\section{Vision}

A peaceful and prosperous West Africa where development is driven by its people.

\section{Mission}

We strengthen civil society in West Africa to be responsive, collaborative, representative, resilient, and influential through knowledge sharing, learning, connecting and influencing.

\section{Wilde Ganzen Foundation}

The Wilde Ganzen Foundation is a Dutch NGO, founded in 1957 with mission to reduce poverty and inequality through community-led initiatives. It supports community-based organisations in the Global South and their Dutch fundraising partners in joint efforts to achieve a better future because it believes communities should have control over their own development. The Wilde Ganzen Foundation utilises more than 60 years of operational experience in international development to promote responsible philanthropy. The Wilde Ganzen Foundation supports social changemakers that are taking on initiatives to fight inequality. They do this through grantmaking, in-depth technical assistance, expertise and their on-the-ground networks. 


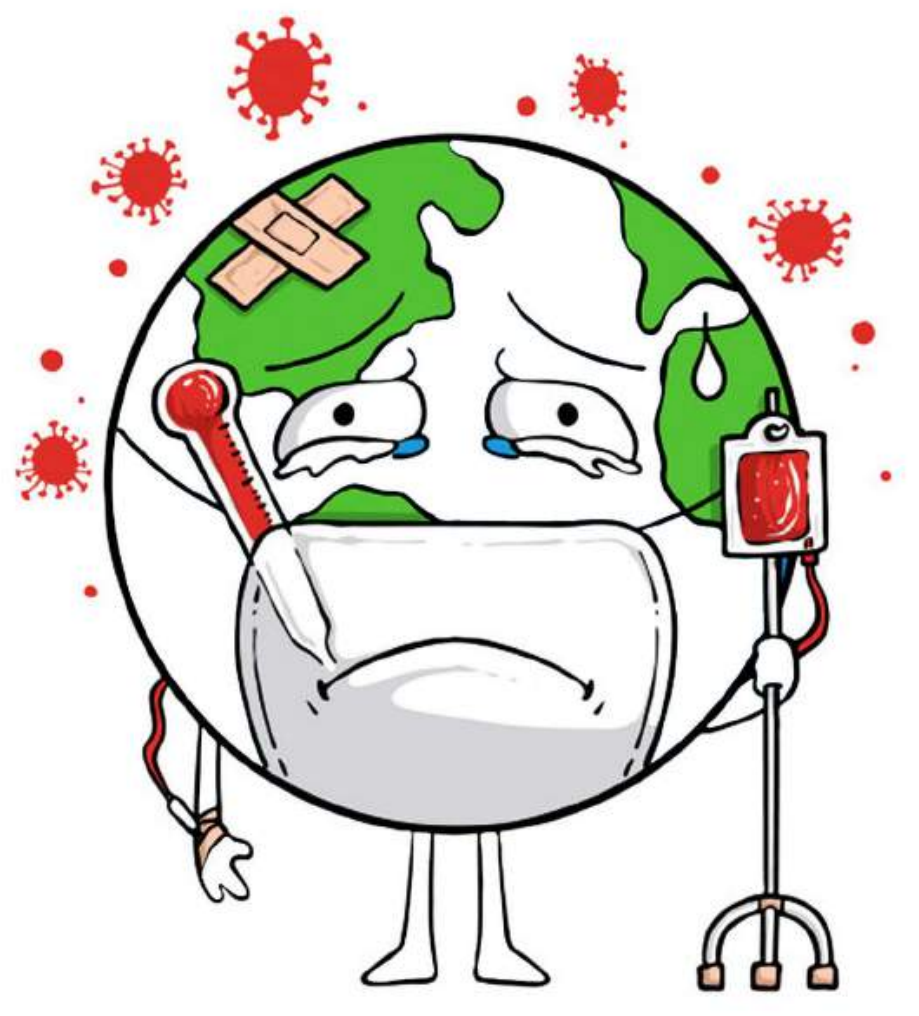

\subsection{Introduction}

This report presents a synthesis of the findings on the impact of the Coronavirus Disease (COVID-19) pandemic on civil society organisations (CSOs) in West Africa, with particular focus on Cameroon, The Gambia, Ghana, Liberia, Nigeria and Sierra Leone . In particular, the report documents how the COVID-19 pandemic has affected CSOs' operations, funding prospects and relationships with donors and stakeholders. Given that CSOs are agile actors with an agency, this report further analyses CSOs' strategic responses for mitigating the effects of the pandemic in ensuring their short-term survival and long-term sustainability. The findings, therefore, present data-based evidence to inform stakeholders' engagement with West African CSOs. The implications of the findings for policy and practice are further discussed.
The findings in this study are informed by a sequential explanatory mixed-method design which involves first collecting and analysing the quantitative data followed by qualitative data. As part of the quantitative phase of this study, a survey questionnaire was administered to 313 CSOs across the six countries (i.e., Cameroon - 36 CSOs; The Gambia - 16 CSOs; Ghana - 86 CSOs; Liberia - 27 CSOs; Nigeria - 80 CSOs; and Sierra Leone - 68 CSOs) between June and July 2020. Following the quantitative data administration and analysis, 6 focus group discussions were conducted with 48 CSOs who first participated in the quantitative phase between July and September 2020. Additional, key informant interviews were conducted as part of the data collection in each country. The final analysis in this report integrated the quantitative and qualitative data, which provided nuanced perspectives on the impact of COVID-19 on CSOs' in West Africa.

Following this introduction, the next section presents a summary of the key findings that emerged from this research. It starts by providing an overview of the surveyed CSOs in the six countries. The second section is followed by the findings on the impact of COVID-19 on CSOs' operations and programmes. Next, the findings on the impact of COVID-19 on funding, domestic resource mobilisation and overall sustainability are presented. The focus then turns to examine how the pandemic has impacted CSO-donor and stakeholder relationships. It also discusses the strategies employed by CSOs in ensuring their short-term survival and long-term sustainability. The final section concludes, following from which key implications and recommendations are identified. 


\section{Key Findings}

\section{1. Types of organisations}

The majority of surveyed CSOs (70.9\%) self-identified as non-governmental organisations (NGOs) across the six countries. For instance, in Ghana, $87.2 \%$ of the CSOs reported being NGOs. The same can be said of Nigeria, where $70.9 \%$ of the surveyed CSOs were NGOs. The second dominant type of CSOs was community-based organisations (CBOs), representing $21.4 \%$ of the surveyed. However, in The Gambia, the dominant organisational form was CBOs which accounted for about $50.0 \%$ of the surveyed CSOs. Other types of CSOs that participated in the survey across the six countries included social enterprises (1.3\%), umbrella organisations (1.3\%) and social movements (1.0\%)..

\section{$70.9 \%$}

Non-governmental organisations (NGOs) across the six countries.

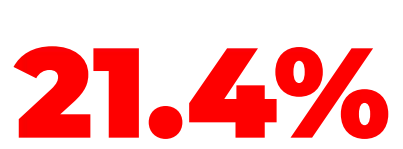

The second dominant type of CSOs was community-based organisations (CBOs).

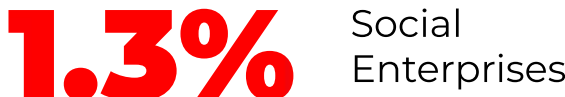

\section{$1.3 \%$ Unthelal}

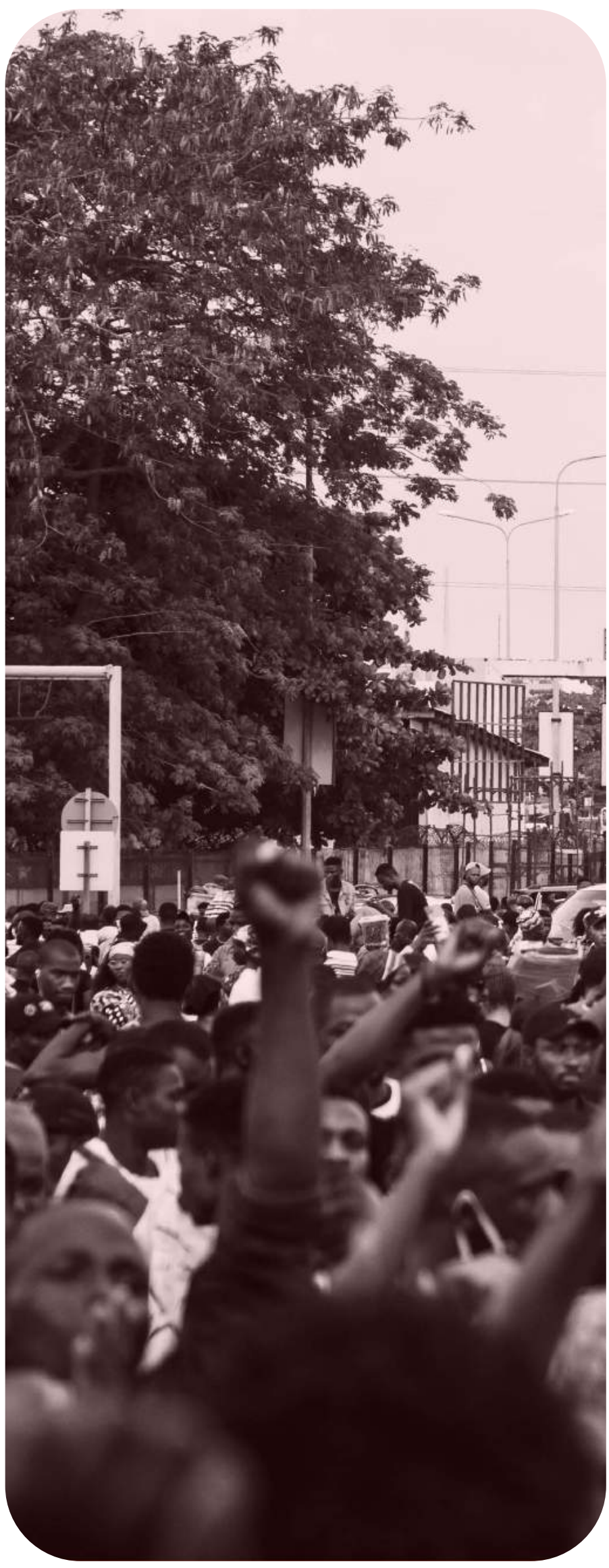

Photo from Nengi Nelson (Unsplash) 


\subsection{Years of Existence and Field of Activity}

Most of the surveyed CSOs (33.5\%) were young and had been in existence between 6-10 years, while a small proportion (8.3\%) had been operating for more than 20 years. This finding is a clear indication of the growth or boom in the number of African CSOs witnessed over the last two decades, as reported in the literature (see, for example, Brass, 2012). The rise of African CSOs has also been attributed to the availability of external donor funding, which has been a 'lifeblood' for their short-term survival and long-term sustainability (Kumi, 2017; Kamstra and Schulpen, 2015).

In terms of field of activity, the survey results indicate that the majority of the CSOs (19.2\%) operated in health, water and sanitation, followed by human rights (17.3\%) and education (15.7\%). Interestingly, across the six countries, only a few CSOs operated in the agriculture and food security (5.8\%) and disability rights (0.6\%) sectors. More importantly, the survey results showed that many CSOs were generalist in their operations where they worked in multiple sectors with their activities reflecting specific community needs.

A chi-square $(X 2)$ test of significance revealed a statistically significant difference between country of origin and sectors of operation $(\mathrm{X} 2=81.06, \mathrm{p}=0.001)$. The cross-tabulation analysis results indicate that the majority of CSOs in Sierra Leone and Cameroon operated in human rights while the focus of Ghanaian and Nigerian CSOs was on education. The thematic areas of operations of CSOs reflect the country's socio-political contexts or environment within which CSOs are located. For instance, in recent years, there have been reported cases of human rights abuses in Cameroon following the Anglophone crisis in Cameroon (Nganji and Cockburn, 2020). CSOs in Nigeria are also known to be active players in the education sector in recent years (see, for example, Keogh et al., 2020; Bello, 2020).
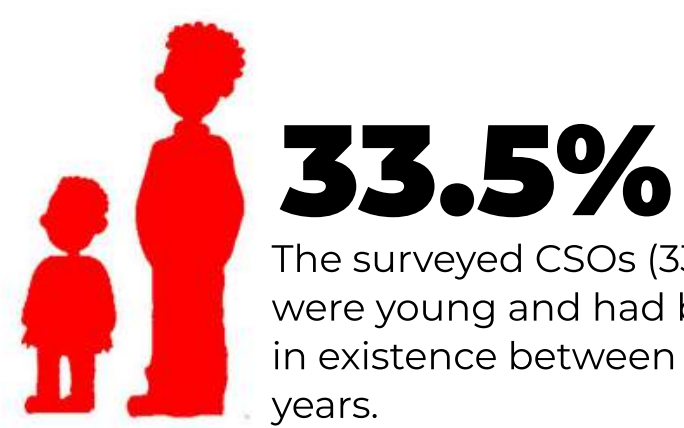

The surveyed CSOs (33.5\%) were young and had been in existence between 6-10 years.
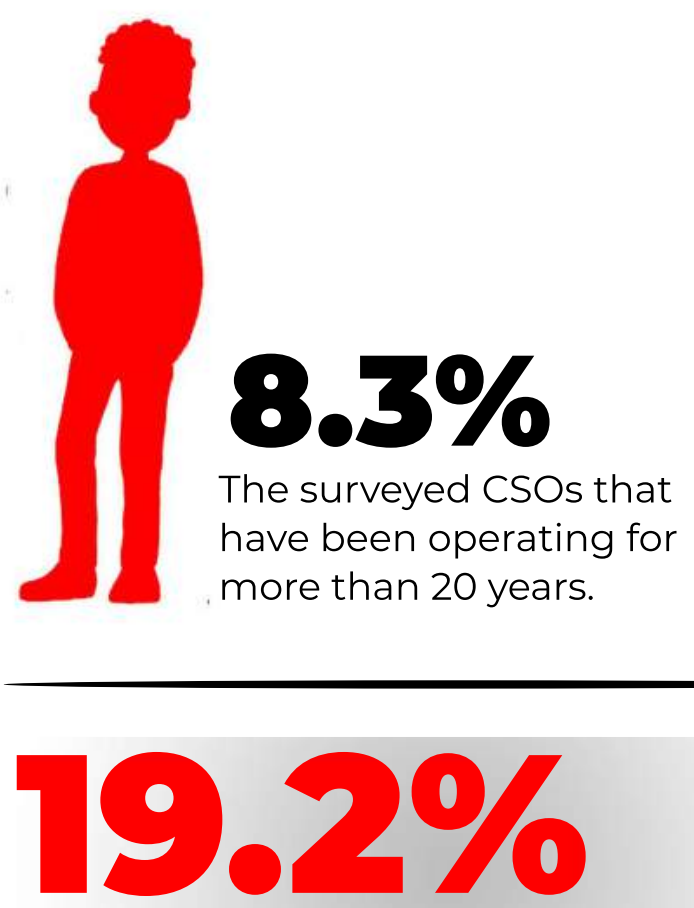

\section{Health, Water and Sanitation}

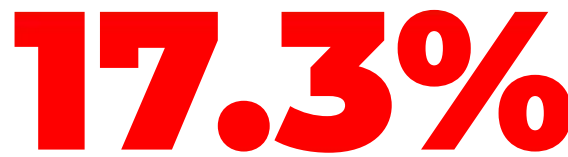

\section{Human Rights}

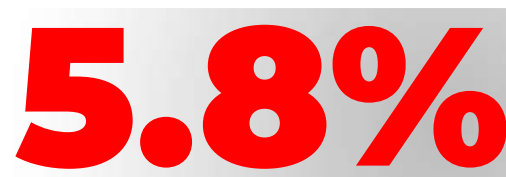

\section{Agriculture \& Food Security}

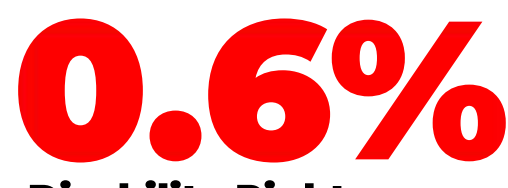

Disability Rights 


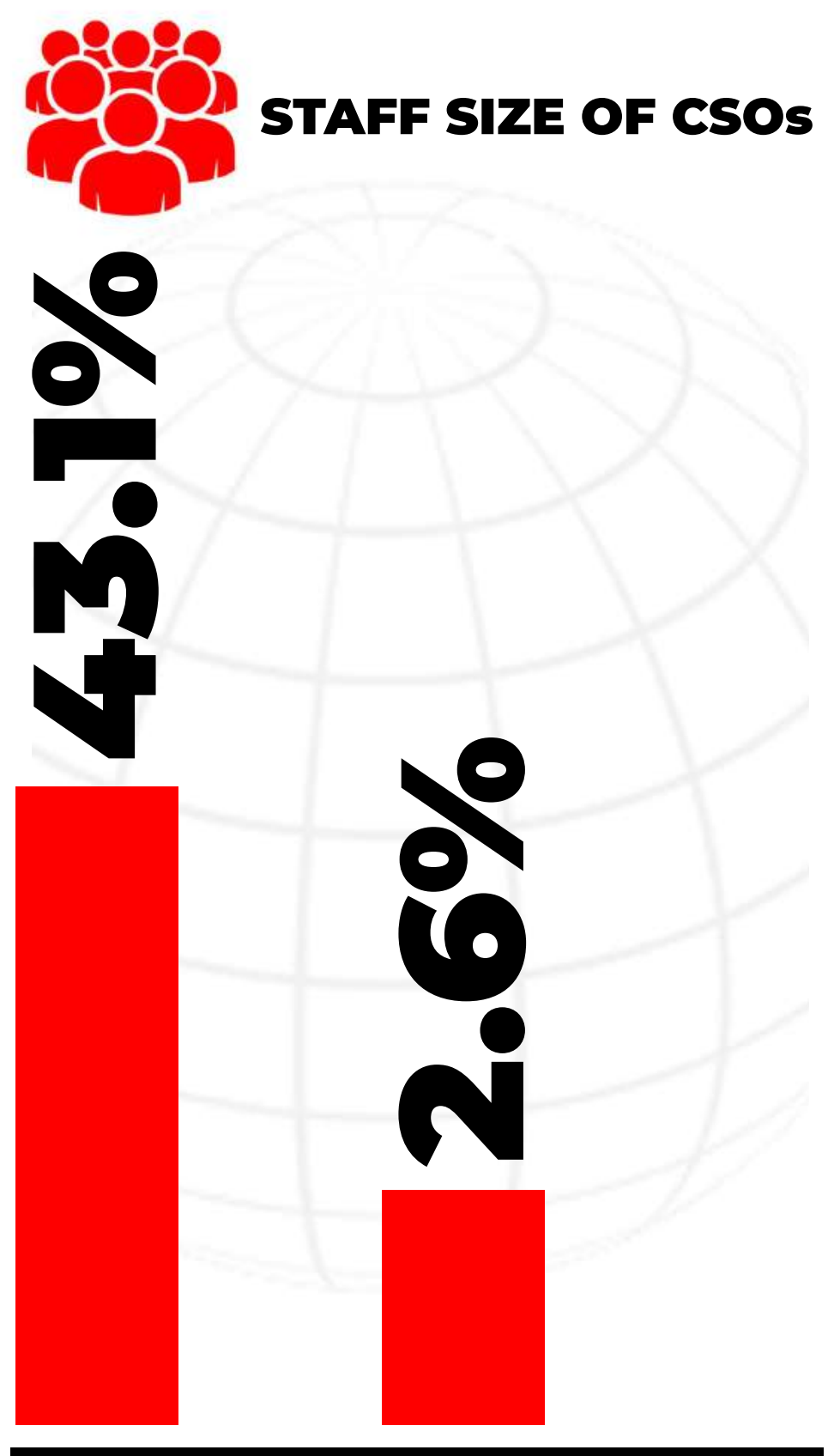

\section{v2.3. Staff Size}

The majority of the surveyed CSOs (43.1\%) were small-sized organisations employing between 1-5 full-time paid staff. Only a few CSOs (2.6\%) operated on a staff strength of between 61-100 employees. The results further indicate variations between countries with regards to the number of staff employed. For instance, in Ghana, Nigeria and Sierra Leone, many CSOs reported having a staff strength of 1-5 employees. The number of CSOs with a staff strength of 61-100 employees was mainly from Nigeria, which is a clear indication that CSOs in Nigeria were relatively medium-to-large sized organisations as measured by the number of full-time paid staff compared to the other countries. The implication of the finding on the relatively small number of paid staff is that many CSOs are unable to hire and retain competent staff due in part to the project-based funding and its associated absence of core funding for supporting institutional development. Indeed, the existing literature has highlighted how the absence of core funding affects the human resource capacity of CSOs through a drastic reduction in paid staff, inability to retain staff and the increasing reliance on volunteer labour (Pousadela and Cruz, 2016; Olawoore, 2017).

$\begin{array}{ll}\text { Small-sized } & \text { Few csos } \\ \text { organisations } & \text { operated on a } \\ \text { employing } & \text { staff strength } \\ \text { between 1-5 } & \text { of between } \\ \text { full-time paid } & 61-100 \\ \text { staff. } & \text { employees. }\end{array}$
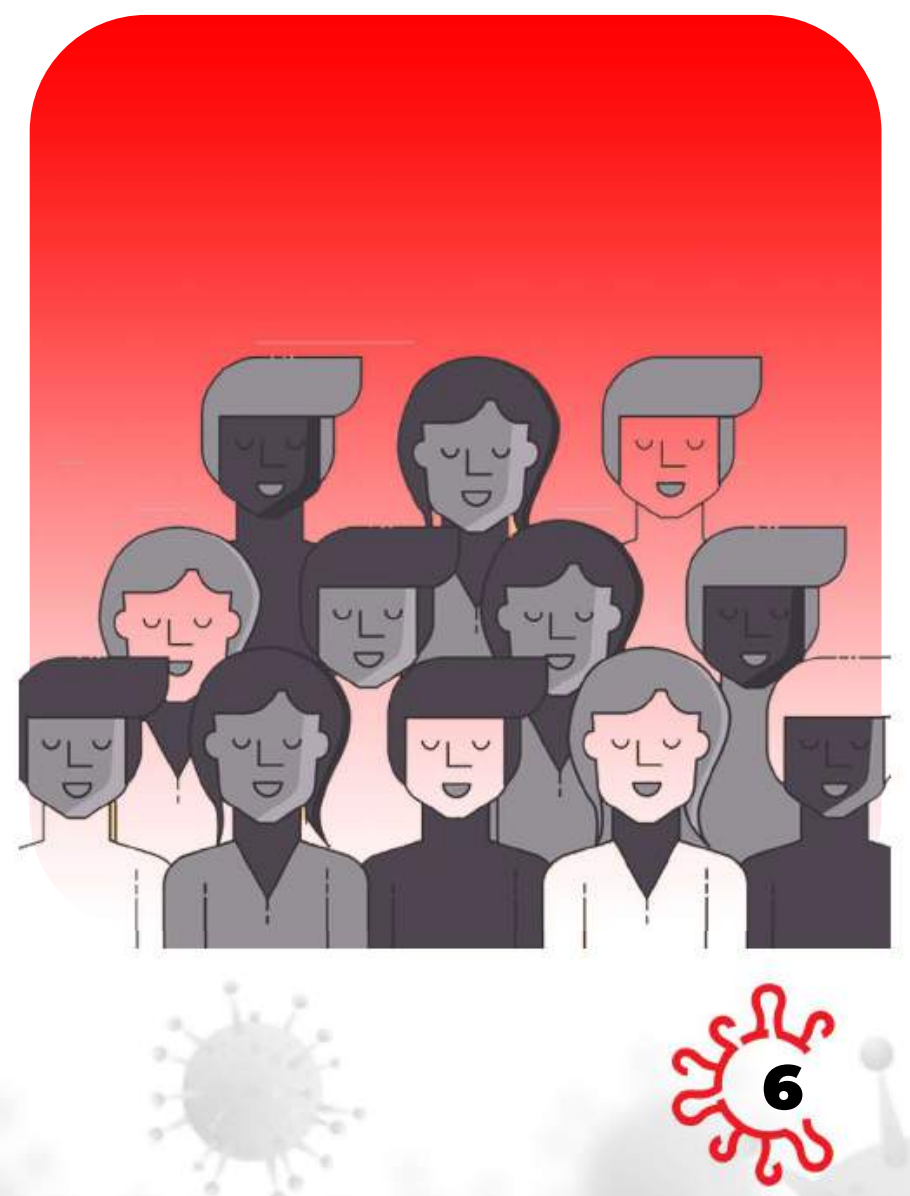


\subsection{CSOs' Current Year Budget and Sources of Income}

Analysis of the survey data indicates that $32.9 \%$ of the surveyed CSOs operated on less than US\$5,000 in 2020. A significant number of CSOs (16.6\%) reported having a budget of between US\$20,001 and US\$ 50,000. However, only a small section of CSOs (5.4\%) had a budget of more than US $\$ 500,000$. There was a statistically significant difference between the annual budget of CSOs and their country of origin ( $X 2=60.47, p=0.005)$. The survey results indicate Ghana and Sierra Leone had a significant number of CSOs (7 for each country out of 17 CSOs) who reported to have operated on a budget of above US\$500,000. On the other hand, of the total 103 CSOs that reported to have operated on a budget of less than US\$5000, 28 (27.1\%) and 25 (24.2\%) were from Nigeria and Sierra Leone, respectively. Overall, the survey results are a clear indication that the majority of the sampled CSOs were small-sized organisations in terms of their financial resources.

With regards to the sources of income, $67.1 \%$ of the surveyed CSOs reported receiving grants from external donors. This finding demonstrates how CSOs in the six countries are highly dependent on external donor funding for their survival. In fact, the existing literature has reported a high donor dependency among CSOs in West Africa (Olawoore, 2017; Kumi, 2017; Arhin et al., 2018; Krawczyk, 2018). Out of the surveyed 313 CSOs, 139 (44.4\%) reported receiving funding from international NGOs (INGOs), 70 (22.4\%) from bilateral and multilateral donor agencies (UN Agencies, DFID, DANIDA etc.). Only a small proportion of CSOs (17.3\%) indicated that they mobilised funding through earned income or income-generating activities. Given their high donor dependency, it was not surprising that the majority of CSOs 203 (64.9\%) reported not mobilising domestic resources in complementing external donor funding during the pandemic.
It is also worthy of note that there was no statistically significant association between country of origin and CSOs' ability to mobilise domestic resources $(X 2=8.39, p=0.590)$. The results show that in Ghana and Nigeria, only 26 (30.2\% of the surveyed CSOs in Ghana) and 33 (41.2\% of the surveyed CSOs in Nigeria) CSOs respectively reported having mobilised domestic resources during the pandemic. However, it is worth mentioning that the different sample sizes for the individual countries might have contributed to the relatively higher number of CSOs from Ghana and Nigeria that reported being able to mobilise domestic resources.
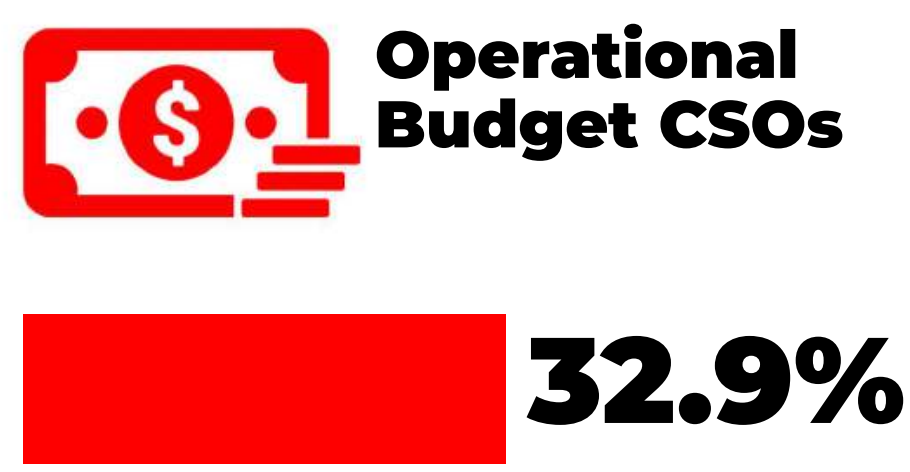

\section{Operated on less than US\$5,000}

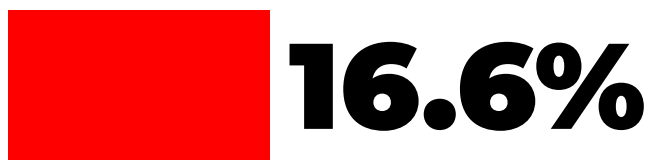

\section{Operated on a budget of between US\$20,001 and US\$ 50,000}
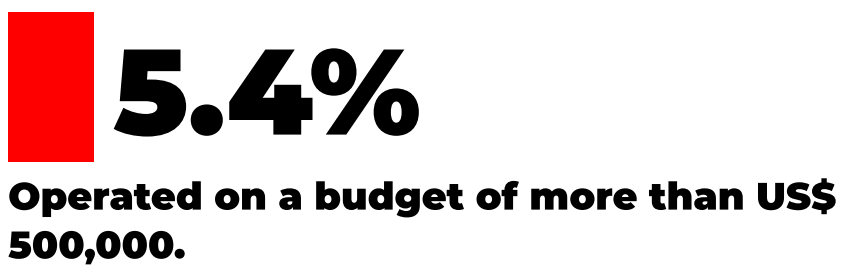


\subsection{Impact of COVID-19 on the Operations and Programmes of CSOs}

\section{1 Short-term effects of the pandemic (1-3 months)}

Across the six countries, an overwhelming majority of CSOs stated that the COVID-19 negatively affected their operations. According to CSO representatives, the COVID-19 pandemic had widespread and swift impacts on their operations, making them vulnerable to uncertainty. In particular, the survey results indicate that the pandemic's negative effects on CSOs' operations occurred through different pathways, such as the closure of offices and its associated adoption of remote working methods. For instance, when asked whether they had to close their office, about 244 (78.0\%) recounted closing their office space due to the imposition of COVID-19 inspired legislations such as lockdowns and the declaration of the state of emergencies. However, the challenge for many CSOs was that before the COVID-19 pandemic, a significant number (221) of them (67.4\%) did not have any policies for remote working. For this reason, many were forced or compelled by the COVID-19 pandemic to implement remote working policies. For instance, the Gambia results showed that $69.0 \%$ of the surveyed CSOs who did not initially have any remote working policies were compelled to introduce some measures where staff could work from home as part of efforts to curb the spread of the pandemic. Similarly, in Cameroon, prior to the COVID-19 pandemic, only $30.5 \%$ of CSOs reported that they had remote working policies but were forced to work remotely when the government implemented COVID-19 inspired legislation. This challenge in turn, put a lot of pressure on staff who were forced to work-from-home and had to joggle between their family responsibilities and working-from-home arrangements such as conducting virtual meetings.

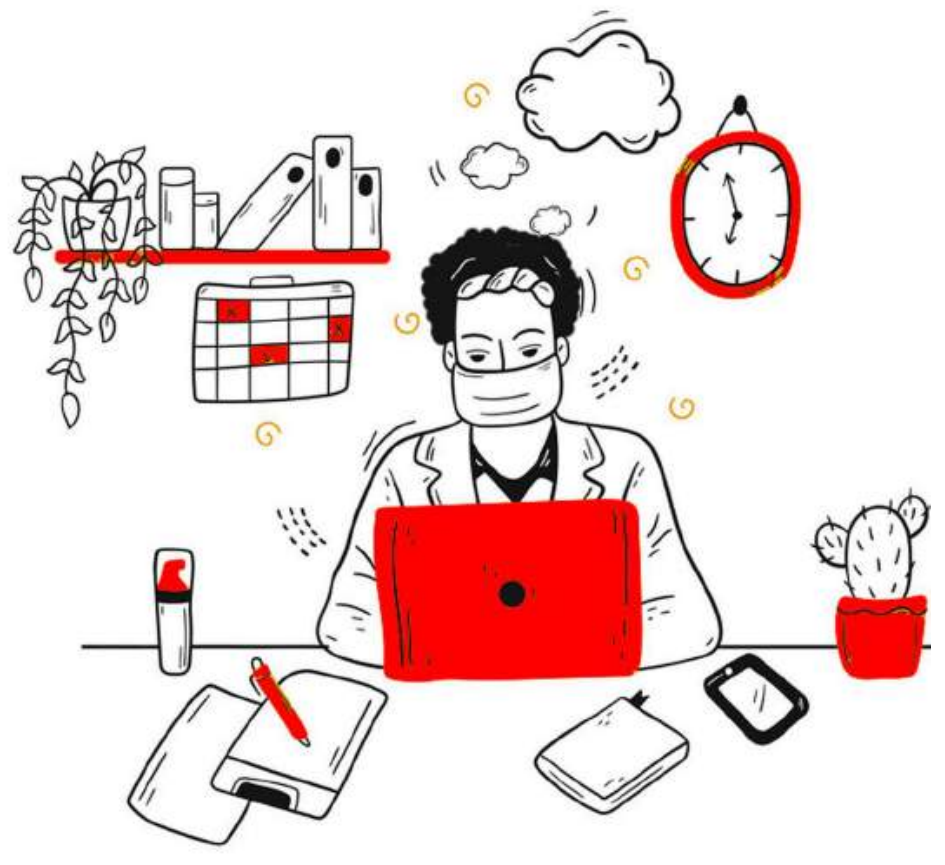

When asked about their preparedness to work remotely, the survey results showed that greater concern for the majority (195) of CSOs (62.3\%) was that they were not prepared to work remotely mainly because they did not have the resources and capacities (computer, internet connectivity and lack of proper training for staff on remote working). In addition, 130 (41.5\%) indicated that the lack of clearly defined remote working policies affected their ability to transition to virtual arrangements. A small proportion of CSOs (14.1\%) also said that the nature of their work did not allow them to work remotely as they often had to engage directly with their intended beneficiaries in delivering their services. Notwithstanding the challenges associated with transitioning to remote working, a few (20) CSOs (6.4\%) reported not experiencing any challenges with working remotely. Overall, the results clearly indicated that the majority of CSOs were not prepared to work remotely and that the COVID-19 pandemic "caught CSOs by surprise".

1 https://wacsi.org/impact-of-covid-79-pandemic-on-civil-society-organisations-in-the-gambia/ 
During the focus group discussion and key informant interviews, some CSO representatives shared the view that the pandemic provided opportunities for enhancing their creativity and innovativeness regarding remote working. The following excerpt from a CSO representative in Ghana captured the state of affairs:

"[.....] it has pushed us out of our comfort zones. It has compelled us to be innovative. Most of us initially thought that working from home was Eurocentric, that it was far from us, and we did not have the logistics to do that. COVID has made us realise that it is possible to deliver without being in the office setting ".

Another CSO representative from Sierra Leone explained that:

"We have reduced the number of staff coming to the office for work per day. We work in shift s. While $50.0 \%$ work in the office, the other $50.0 \%$ work from home, and we use email to communicate and make our work easier, and we do zoom meetings".

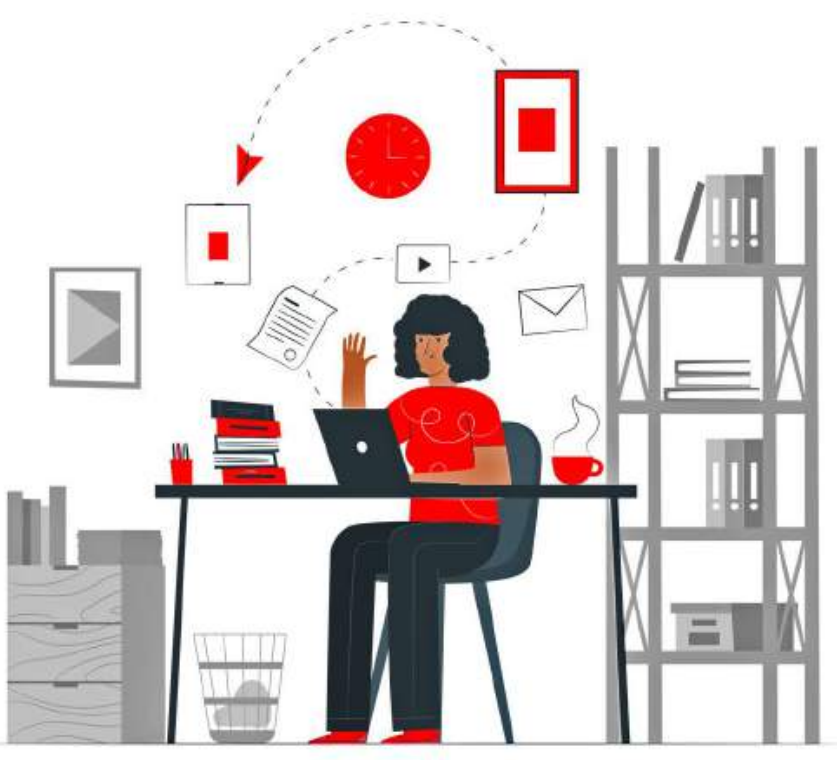

Aside from the impact of COVID-19 on CSOs' working arrangements, it also affected their short-term operations. Specifically, the imposition of COVID-19 inspired legislation meant that CSOs could not undertake their projects and programmes in "normal ways, " which led to operational difficulties. For this reason, a majority of CSOs (64.9\%) reported restrictions on staff movement, cancellation of meetings and conferences (64.2\%), reduced staff strength (29.4\%), reduced or cancelled operations such as training and workshops (70.6\%), cessation of fieldwork and inability to have community interactions (56.7\%). Surprisingly, during the pandemic, a section of CSOs (21.1\%) reported increased demand for their services as communities and intended beneficiaries sought relief items to help them cope with the pandemic. In particular, the empirical evidence suggests that the COVID-19 pandemic created opportunities for CSOs to engage in other activities which were not part of their initial programmes, such as online training, training in digital tools and remote working, health promotion and education and advocacy for human rights. This finding chimes with existing studies that highlight that despite the cessation of 'CSOs' operations and programmes in the short-term, the demand for their services witnessed a dramatic increase (EPIC Africa and African NGOs, 2020; Tusev, 2020). Other short-term impacts mentioned by CSOs included loss of funding (45.7\%) and increased organisational costs (27.5\%). Despite the negative short-term effects, a section of CSOs $12 \quad(3.8 \%)$ reported experiencing minimal or no effects of the pandemic on their operations and programmes.

2 https://wacsi.org/impact-of-covid-79-pandemic-on-civil-society-organisations-in-cameroon/

3 https://wacsi.org/impact-of-covid-19-pandemic-on-civil-society-organisations-in-ghana/

4 https://wacsi.org/impact-of-covid-19-pandemic-on-civil-society-organisations-in-sierra-leone/ 

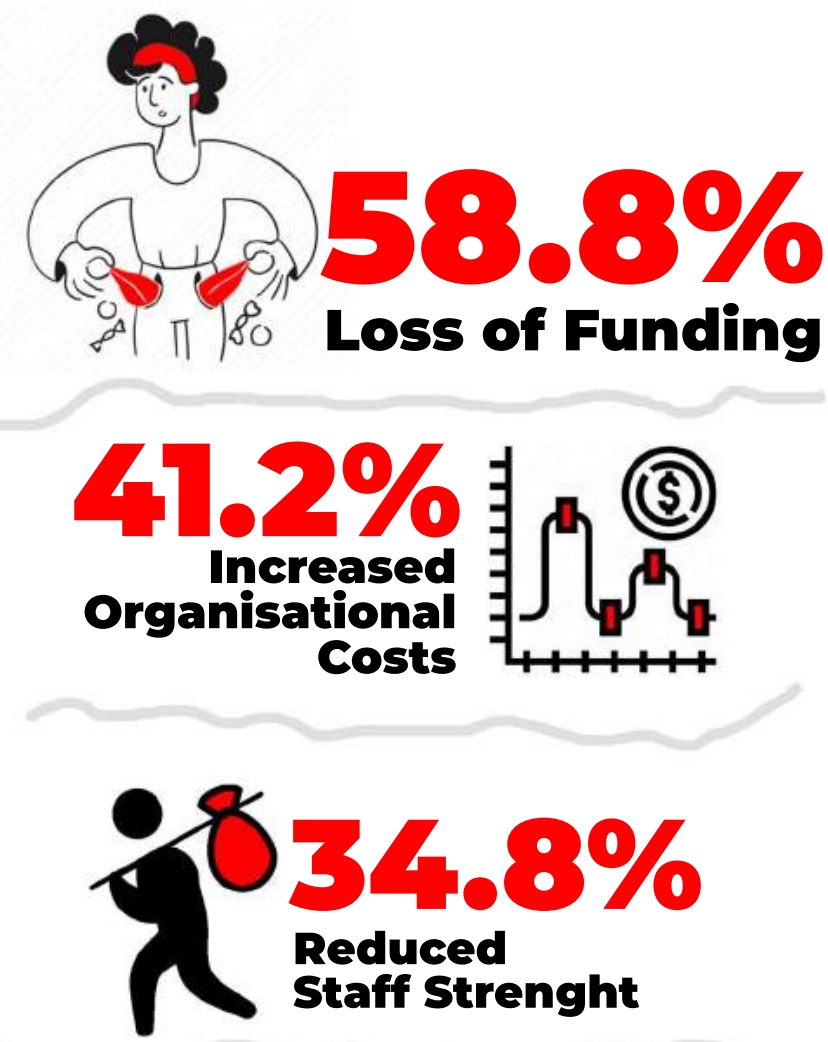

\section{$50.8 \%$ Cancellation Meetings \& Travels}
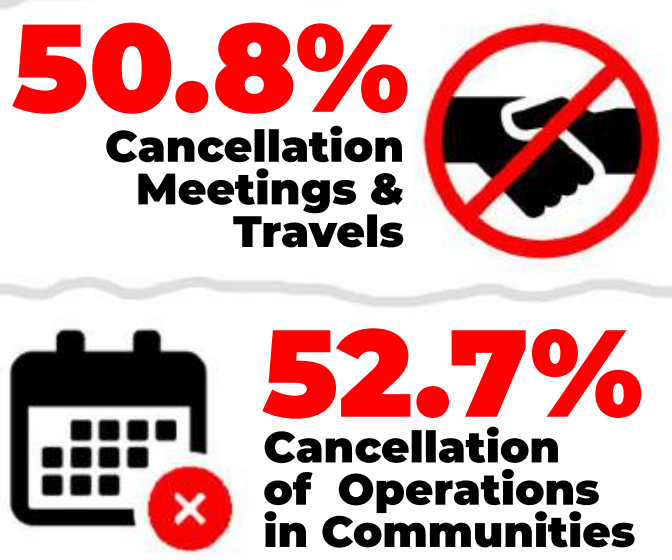

\subsection{Long-term Effects on CSOs' operations and programmes (6-12 months)}

With regards to the anticipated long-term effects of the COVID-19 pandemic, based on the survey results shown across the six countries, many CSOs (58.8\%) indicated a loss of funding as a result of changes in donor priorities; increased organisational costs (41.2\%); reduced staff strength (34.8\%); cancellations of meetings and travels (50.8\%) and reduction or cancellation of operations in communities (52.7\%). Loss of funding was reported as the top-most long-term impact of the pandemic on the operations of CSOs.
Notwithstanding, there was no significant association between a loss of funding as a result of COVID-19 and country of origin (X2= 10.54, $p=0.06$ ). Thus, the possibility of CSOs reporting loss of funding as a result of COVID-19 was not determined or influenced by the country in which they operated. For instance, a cross-tabulation analysis showed that 48, 46, and 40 CSOs from Ghana, Sierra Leone, and Nigeria respectively indicated that they anticipated loss of funding as the pandemic's long-term impact on their operations. The effect of loss of funding is the inability of CSOs" to retain their staff in the absence of funds. As the empirical evidence demonstrates, the loss of funding has compelled some (83) CSOs (26.5\%) to furlough or dismiss their staff as a cost-saving strategy to ensure their own organisational sustainability. Surprisingly, the survey results clearly indicated that Sierra Leone had the highest amount of CSOs (31) that reported furloughing or dismissing their staff as a result of loss of funding. Other countries included Nigeria (26), Ghana (14) and Liberia (7). In the case of Ghana, during focus group discussion (FGDs), a CSO representative explained the decision of the organisation to dismiss some staff by stating that:

There are some people [staff] who were asked that look, your project cannot get funding, so we have to stop you from working. So, there are some people [staff] who had to exit because their project could not continue to get funding, so we have to get you to exit.

Similarly, in Sierra Leone, it was reported that the Foundation for Integrated Development - Sierra Leone (FID/SL) had to dismiss some employees mainly because of reduced funding opportunities caused by the COVID-19 pandemic . 


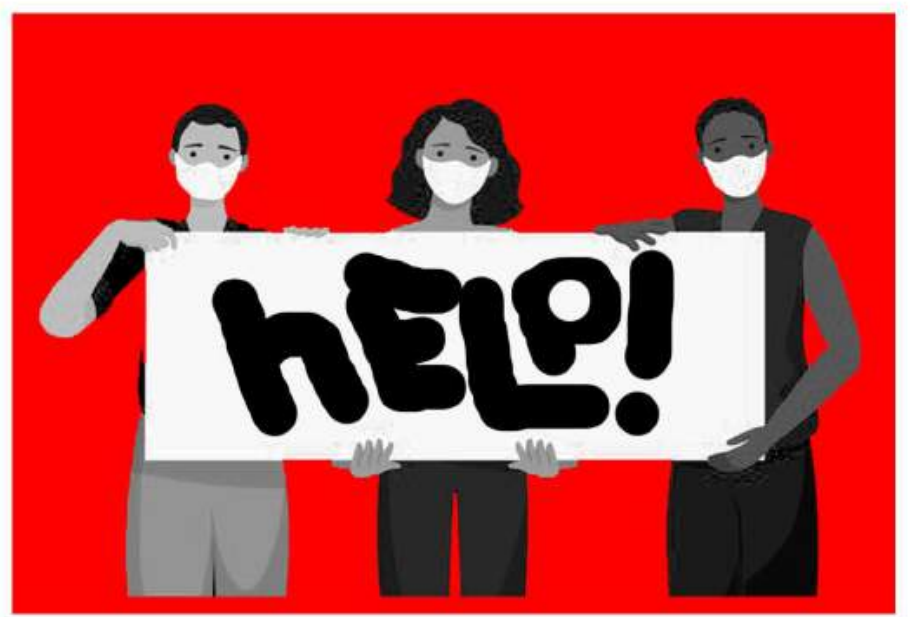

Another long-term effect was CSOs inability to deliver services to their intended beneficiaries. Results showed that 148 (47.3\%) and 97 (31.0\%) of the surveyed CSOs reported experiencing severely reduced capacity and moderately reduced capacity in meeting the needs of their intended beneficiaries, respectively. Only a small proportion of CSOs, 10 (3.2\%), mentioned that their ability to provide services had not been affected at all by the COVID-19 pandemic. This finding clearly indicates that in the long-term, the pandemic slowed the work of CSOs and their ability to respond to their intended beneficiaries' needs, which in turn has the potential of negatively affecting their legitimacy and relationships with intended beneficiaries because of their inability to meet their needs.

In safeguarding their operations against the effects of the pandemic, many CSOs 172 (55.0\%) mentioned that they had taken appropriate measures. However, some CSO representatives (54.3\%) explained that they had some difficulties adapting to such measures, while a section (31.9\%) also experienced great difficulty. Interestingly, a proportion of the surveyed CSOs 116 (37.1\%) also felt that they had taken a few steps in safeguarding their operations from the effects of the pandemic.

\subsection{Effect of COVID-19 pandemic on CSOs' funding, domestic resource mobilisation and sustainability}

All CSOs surveyed reported being impacted by the COVID-19 pandemic with regards to their funding situation. According to the survey data, delayed or reduced funding from donors was the dominant or top-most impact of COVID-19 as $42.2 \%$ of CSOs reported experiencing this phenomenon. As reported by a section of CSOs (41.5\%), another effect was funding restrictions and constraints that included cancelled donations. Interestingly, the consensus among the CSOs that participated in the quantitative and qualitative research was that COVID-19 would affect their organisational funding in the next 3-6 months. For instance, in the quantitative phase of the research, most CSOs (48.6\%) and $32.3 \%$ ) agreed and strongly agreed that the pandemic would affect their funding prospects. CSO representatives iterated this concern during the focus group discussions and key informant interviews. On the other hand, a section of CSOs (11.2\%) neither disagreed nor agreed that their funding will be negatively affected by the pandemic.

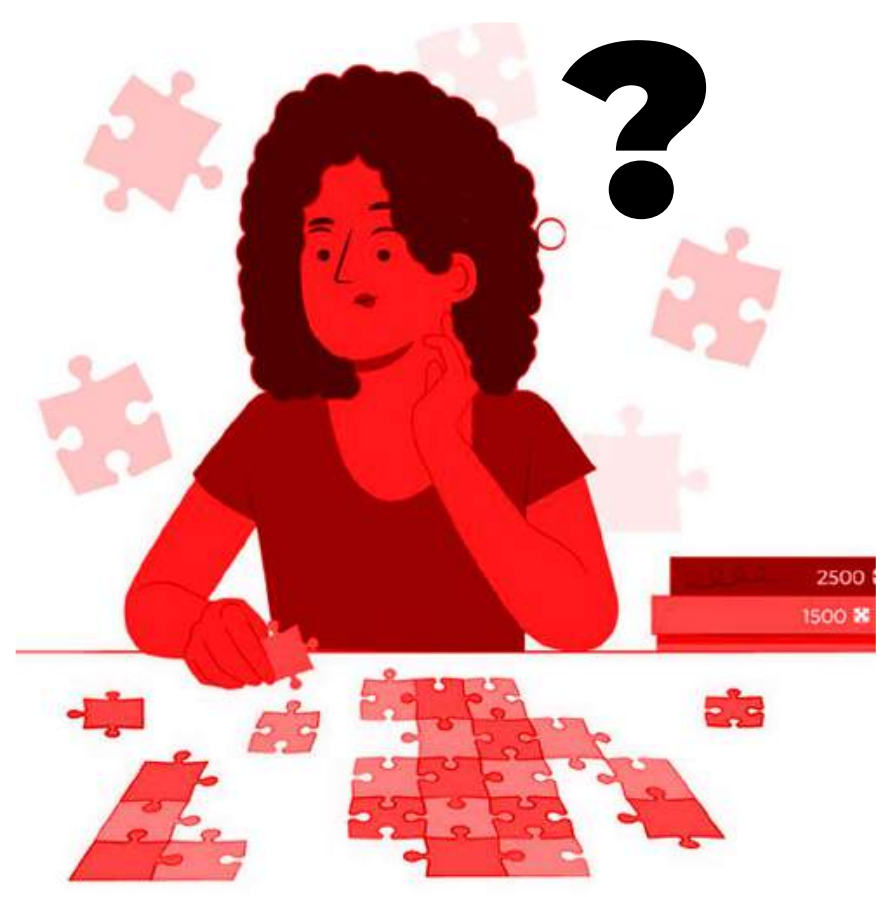



The qualitative data also provided some useful insights into the challenges faced by CSOs in their attempt to mobilise domestic resources. Among them included the lack of trust, accountability and the weak relationship between CSOs and corporate organisations. These findings chime with existing studies on the challenges faced by CSOs in mobilising domestic resources (see, for example, Kumi, 2019; Vandyck, 2020; Pandya and Ron, 2017). Informed by the inability of CSOs to mobilise domestic resources coupled with dwindling donor funding. When asked whether CSOs felt distressed about their long-term sustainability, the majority of CSOs, 156 (49.8\%) and 117 (37.4) stated that they agreed and strongly agreed, respectively, with the statement. When probed further about the pandemic's overall impact on the sustainability of the CSO sector in general in each country, the response 165 (52.7\%) was that the COVID-19 pandemic would, to a very high extent, negatively affect the CSO sector. However, there was no statistically significant difference in respondents' responses in the six countries $(X 2=25.57, p=0.18)$. This finding is a clear indication that irrespective of the country within which the CSO was located, there was no significant difference in their perception of how the pandemic would affect the CSO sector's sustainability. The findings demonstrated that the COVID-19 pandemic would have devasting effects on the sustainability of individual CSOs and the sector within which they operate. Similar findings have been reported elsewhere in the literature (Epic Africa and African NGOs, 2020).

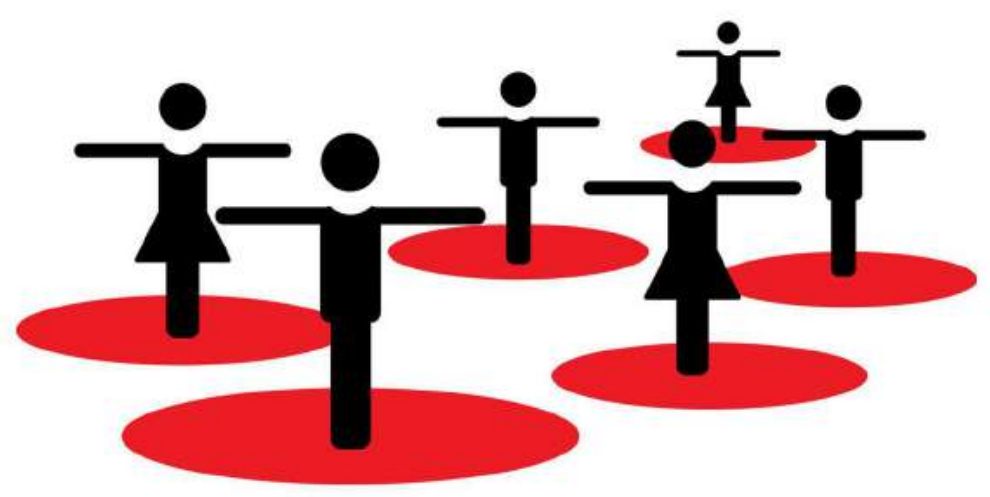

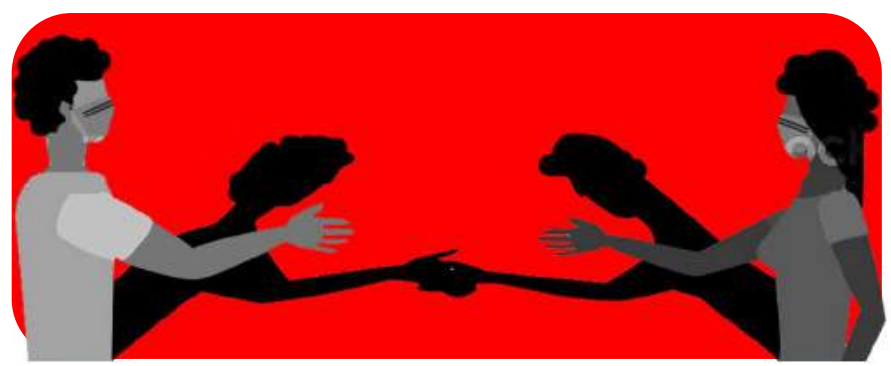

\subsection{Impact of the COVID-19 Pandemic on} CSO-donor and Stakeholder Relations

Across the six countries, respondents were asked how the pandemic had affected their relationships with their donors. In particular, the survey focused on issues such as communication with donors in terms of changes in project activities, donor funding priorities and flexibility of donor funding requirements and arrangements amidst the pandemic. $46.0 \%$ of the surveyed CSOs stated that their donors had communicated or informed them that the COVID-19 pandemic would potentially affect their ability to continue their support for the organisation in the short-term and long-term .

When asked about whether donors would change their funding priorities, a majority of CSOs (38.3\%) agreed to the statement. 34.5\% of CSOs also reported that they neither disagreed nor agreed that donors would change their funding priorities. More importantly, with regards to communication with donors, the results indicated that the most significant concern of CSOs included seeking extension of project completion dates from their donors (39.3\%), discussing details regarding the use of donor funding (23.3\%) and discussing cancellation of project activities with donors (13.4\%). On the other hand, a larger proportion of CSOs (43.1\%) reported that they had not discussed any topics with their donors concerning the impact of the COVID-19 pandemic on their relationships. CSOs were also asked to rank their perception of donors' flexibility in meeting their needs. 


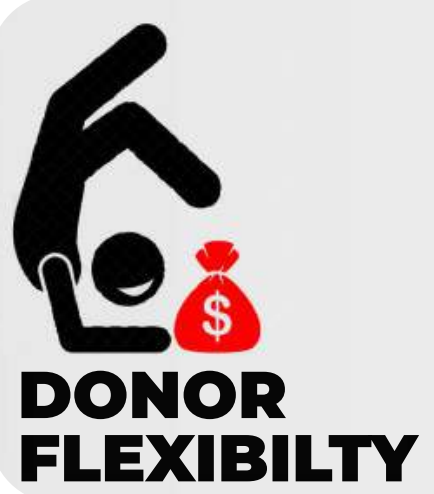

The survey results showed that 126 (40.3\%) responded that donors were very flexible, while 16 (5.1\%) said donors were extremely flexible. On the other hand, 91 (29.1\%) chose neither flexible nor not flexible, while 45 (14.4\%) responded that donors were not flexible.

Among the majority of CSOs 213 (68.1\%), their top-most need requiring assistance from donors was technology support (e.g., moving programmes online). For others, their needs included re-evaluating fundraising strategies 200 (63.9\%), sharing of real-time data with stakeholders 80 (25.6\%), coaching session in leading in ambiguity 80 (25.6\%), financial scenario planning 144 (46.0\%), wellness and self-care 81 (25.6\%), guidance to the board of directors 58 (18.5\%), human resource management 118 (37.7\%) and volunteer recruitment 150 (47.9\%). Data from the focus group discussions and interviews suggested the need for greater investment by donors in the technological capacities of CSOs. This suggestion is largely because many CSOs reported that they have resorted to using online platforms in undertaking their activities.

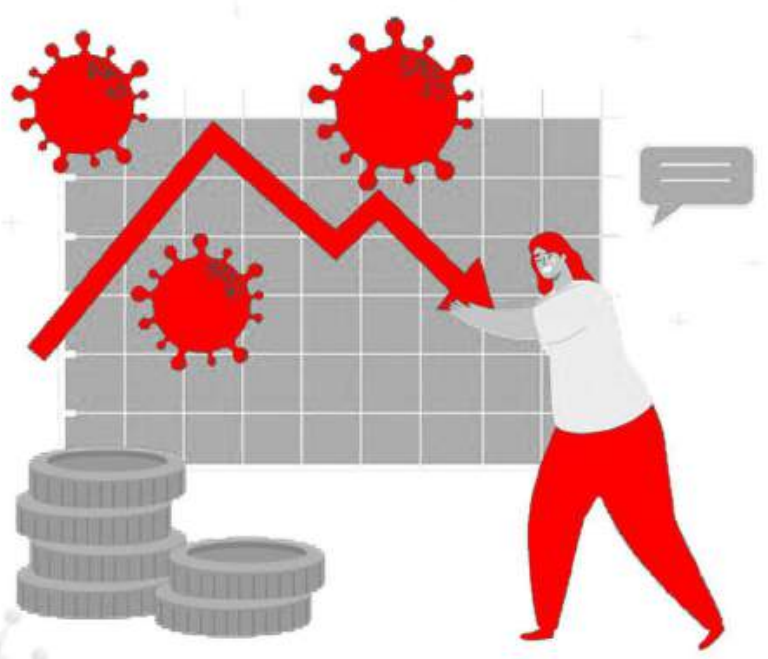

\subsection{Overview of CSOs' responses and strategies to the COVID-19 pandemic}

\subsection{Strategies to mitigate the effects of COVID-19 on CSOs' operations}

Interview data suggests that CSOs adopted a number of strategies to ensure their short-term survival and long-term sustainability. In doing so, the strategies were targeted at mitigating the effects of the pandemic on their operations and programmes, funding and relationship with donors and stakeholders, including intended beneficiaries. Across the six countries, there were similarities in the responses employed by CSOs, especially on the adoption of cost-reduction strategies such as downsizing of staff, reducing existing programmes and services to intended beneficiaries, reliance on the use of digital technologies, reliance on operating reserves and the suspension of upcoming programmes.

\subsection{Strategies to mitigate the effects of COVID-19 on funding}

Among the strategies employed by CSOs include mobilising domestic resources (i.e., financial and non-financial resources) in complementing donor funding. In particular, many CSOs had to rely on the services of volunteers to undertake their activities in communities, while others resorted to mobilising resources online using crowdfunding platforms as well as engaging in income-generating activities through social enterprises. Other strategies included reducing administrative and programme expenses through the suspension of outreach programmes in communities. 
For this reason, the analysis of the survey and interview data suggested that the mobilisation of alternative or domestic resources and the cost-reduction were the two main strategies employed by CSOs across the six countries to mitigate the impacts of the pandemic on their finances. In fact, existing studies have highlighted how CSOs adopt cost-cutting or reduction strategies during periods of financial difficulty (Arhin et al., 2018; Elbers and Arts, 2011). Other strategies adopted by CSOs to ensure their financial resilience revolve around reliance on operating reserves in the short -term. Organisations are known to depend on their reserves when faced with financial uncertainty and their associated vulnerability. Operating reserves also help CSOs maintain spending in line with long-term organisational goals (Sloan et al., 2016; Kim and Mason, 2020).

\subsection{Strategies to mitigate the effects of COVID-19 on donor and other stakeholder relations}

Confronted with the effects of the pandemic on their relationships with stakeholders, including donors, some CSOs developed strategies by engaging in constant communication and interactions with their donors through emails, digital platforms, investing in relationship building mechanisms such as having a dedicated staff to communicate with donors and mainstreaming COVID-19 related programmes suggested by donors into their operations. As the evidence from this study suggests, CSOs have also adopted partnerships or collaborations with like-minded organisations during the pandemic. For instance, in Liberia, some CSOs have conducted stakeholder mapping to identify stakeholders such as government agencies, community leaders etc., that could work together with them .
Similarly, in Sierra Leone, CSO representatives reported seeking collaborations in advocating policy changes, capacity building, awareness-raising, and working together with local community leaders to distribute personal protective equipment and food items to communities in need and educating the public on preventive measures. However, while CSOs have deepened their collaborations with stakeholders across the six countries, their engagement and involvement in policy formulation on COVID-19 were very weak. In some instances, they were not even consulted by governments in COVID-19 related policy formulation and implementation. This finding also raised questions about the extent of collaboration between governments and CSOs across the six West African countries.

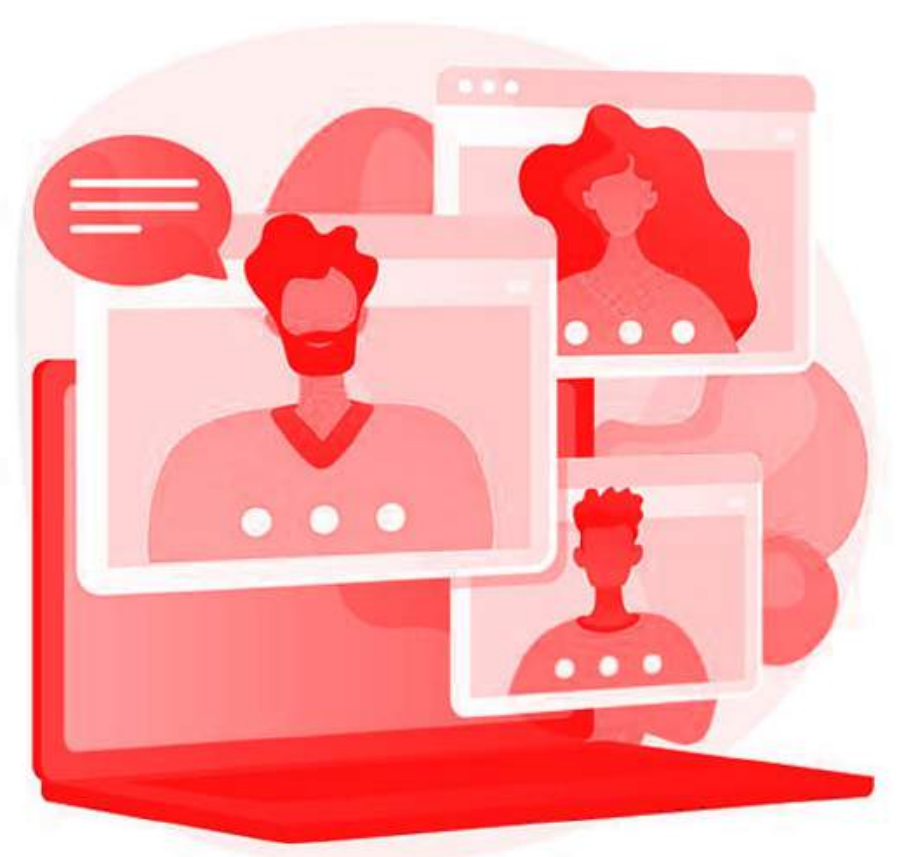

8 See the country reports for a detailed analysis of the strategies employed by CSOs. 


\subsection{Conclusion}

This study sought to examine the impact of the COVID-19 pandemic on CSOs in six West African countries (Nigeria, Ghana, Sierra Leone, Liberia, The Gambia and Cameroon ). The study drew on a sequential explanatory mixed methods design involving first collecting and analysing quantitative data followed by qualitative data. In total, 313 CSOs and 48 CSOs participated in the research's quantitative and qualitative phases, respectively. The study has shown that the COVID-19 pandemic has had devasting effects on CSOs' operations, funding and relationships with donors and stakeholders. This effect has the potential of negatively affecting their organisational sustainability in the short-term. Notwithstanding the potentially negative effects, the COVID-19 pandemic has also provided opportunities for CSOs to become more agile and resilient actors able to withstand uncertainties. More specifically, for West African CSOs, the COVID-19 pandemic could be considered as a positive disruptive change' because of its ability to cause radical and transformational changes in their operations. As clearly demonstrated in this study, the pandemic has caused CSOs to re-orient their operations by incorporating and adopting innovative and new ways of working, especially with digital technologies. For instance, many CSOs adapted to working remotely, which, while recognising its challenges, provided opportunities for CSOs to continue their operations during the pandemic. Thus, the pandemic has accorded CSOs the platform for creativity and innovativeness.

More so, the pandemic has reinforced the need for a deliberate investment in digital technologies by CSOs and their donors. As the findings in this study demonstrate, many CSOs struggled to transition to digital technologies in the initial stages of the pandemic because of the lack of investments.
The findings also highlight how investments in digital technologies could harness the work of CSOs by increasing their visibility and reputation, especially with the use of social media in raising awareness about the pandemic, engaging in active advocacy on public policies, and meeting the needs of their intended beneficiaries. More importantly, it demonstrates how CSOs could use technology to leverage their resource mobilisation efforts, especially through online platforms. The findings call into question the need for conscious efforts to invest in the digital technologies of CSOs. For instance, organisations such as WACSI and TechSoup could provide capacity strengthening initiatives for CSOs on the use of digital technologies to deliver their programmes.

Thirdly, the pandemic has reinforced the need for CSOs to increase their mobilisation efforts to mobilise domestic resources as an alternative route and complement external donor funding. As the findings highlight, the pandemic created financial uncertainty and its associated vulnerability, especially for donors. The pandemic, in turn, affected their ability to provide the needed resources for CSOs who are highly dependent on their funding for survival. However, what emerges strongly from this study is the potential of domestic resources such as community volunteering and individual and corporate funding to complement external donor funding. The effective mobilisation of domestic resources by CSOs also requires creating an enabling environment that encourages local giving. This domestic mobilisation strategy will also depend on promoting incentives and creating legal frameworks by West African governments. Moreover, CSOs also need to invest in their technical and human capacity and accountability and transparency mechanisms to mobilise domestic resources effectively. 


\subsection{CSOs' view on support needed from stakeholders}

\section{Support needed from Donors}

1. Strengthening the capacity of CSOs in digital technologies

The majority of the CSOs in this study suggested the need for donors to support them in acquiring soft and hard information technology infrastructure to support operations. They mentioned that a deliberate investment by donors in digital technologies would go a long way in helping them deliver efficiently and effectively on their programmes.

\section{Investment in building the institutional} capacity of CSOs to adapt to complex and uncertain environments

A concern raised by CSOs was the need for donors to invest in the institutional strengthening of CSOs. This approach also requires donors to create room for flexibility in their funding arrangements by taking into consideration capacity needs of CSOs when providing funding for their projects. It wa suggested that donors could provide cor funding as part of their effort to strengthe the institutional capacity of CSOs. Donor could also share information or knowledge o best practices on how CSOs elsewhere adak to uncertainty in their operating environmen Moreover, it was suggested that donors focu on building the capacity of CSOs, especially, i working remotely and engaging CSOs 0 crises management and the institution $c$ legal frameworks.

3. Provision of support towards the mobilisation of domestic resources

CSO representatives suggested that donor need to provide the needed suppor (technical, material and human) that woul enable them to mobilise resource domestically or locally to advance their work.
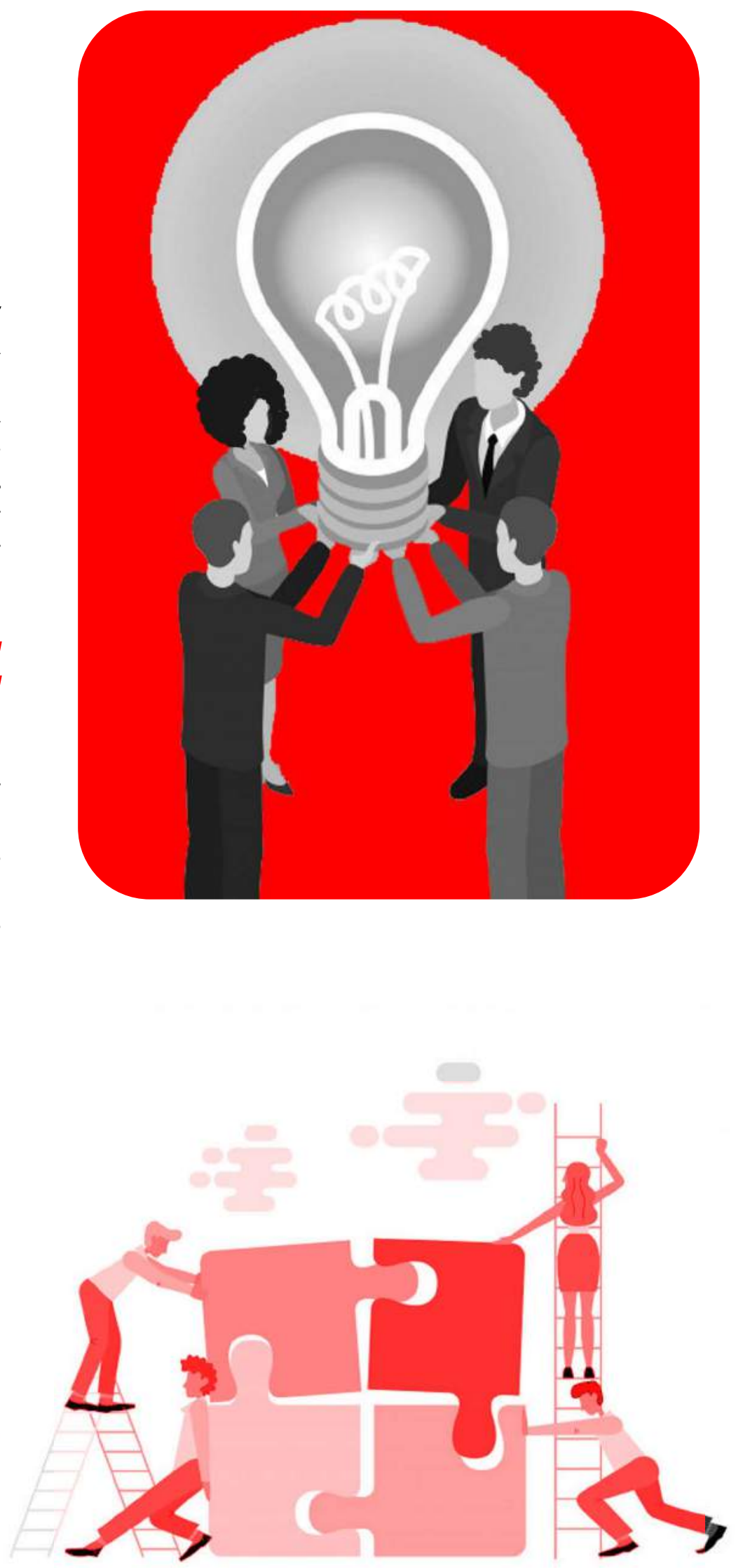


\section{Support needed from WACSI}

1. WACSI should commit to providing capacity through training and mentorship for the CSOs, especially those at the community level. This capacity enhancement will ensure that the organisations are equipped with the requite knowledge to manage their resources better and engage their communities of beneficiaries.

2. WACSI should provide capacity strengthening initiatives for CSOs in resource mobilisation and leadership.

\section{Support needed from National Government}

1. Governments need to support and enhance the operational capacity of CSOs through national emergency funding mechanisms and provide capacity-building opportunities. In addition, they should provide resources for national pandemic preparedness, capacity development, and response measures.

2. Provide holistic and systemic approaches in the fight against the COVID-19 pandemic and other emergency situations. These approaches will include education, human rights, gender, and social protection issues. It also requires governments to create an enabling environment for stronger support and cooperation between CSOs and government in responding to the challenges posed by the pandemic.

3. Leverage and utilise CSOs' experience and expertise in planning, coordinating and implementing national responses to the COVID-19 pandemic.

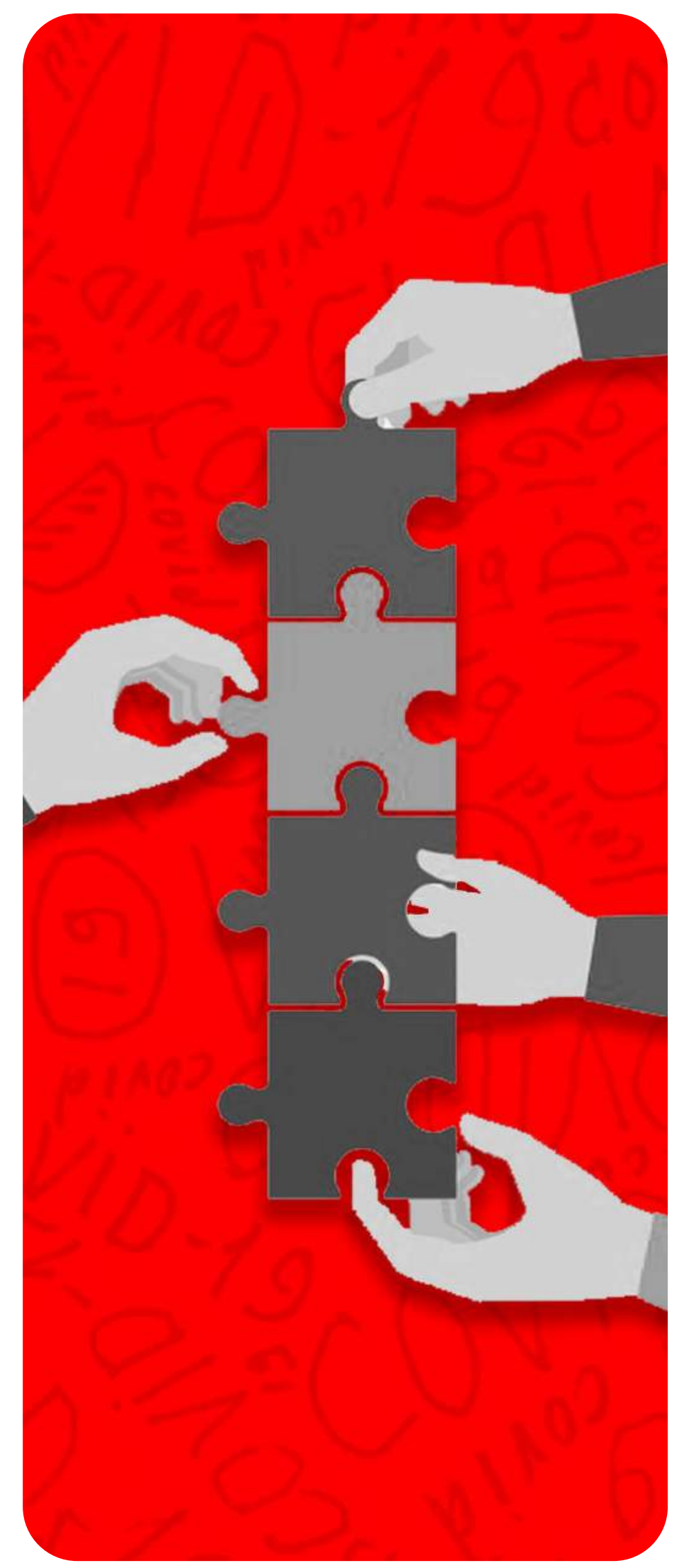




\section{References}

Arhin, A. A., Kumi, E., \& Adam, M. A. S. (2018). Facing the bullet? Non-governmental organisations' (NGOs') responses to the changing aid landscape in Ghana. VOLUNTAS: International Journal of Voluntary and Nonprofit Organisations, 29(2), 348-360.

Bello, I. (2020). Sustainable development goals (SDGs) for education in Nigeria: an examination of Etisalat corporate social responsibility in Nigeria's post-basic education sector. International Journal of Lifelong Education, 1-14. https://doi.org/10.1080/02601370.2020.1836051

Brass, J. N. (2012). Blurring boundaries: The integration of NGOs into governance in Kenya. Governance, 25(2), 209-235.

Calabrese, T. (2013). Running on empty: The operating reserves of US nonprofit organisations. Nonprofit Management and Leadership, 23(3), 281-302

EPIC Africa and African NGOs (2020). The impact of COVID-19 on African civil society organisations: Challenges, Responses and Opportunities. EPIC Africa. Retrieved from: https://staticl.squarespace.com/static/5638d8dbe4b087140cc9098d/t/5efabc7884a29a20185fcba f/1593490570417/The+Impact+of+Covid-19+on+African+Civil+Society+Organisations.pdf

Kamstra, J., \& Schulpen, L. (2015). Worlds apart but much alike: Donor funding and the shomogenisation of NGOs in Ghana and Indonesia. Studies in comparative international development, 50(3), 331-357.

Keogh, S. C., Leong, E., Motta, A., Sidze, E., Monzón, A. S., \& Amo-Adjei, J. (2020). Classroom implementation of national sexuality education curricula in four low-and middle-income countries. Sex Education, 1-18. https://doi.org/10.1080/14681811.2020.1821180

Kim, M., \& Mason, D. P. (2020). Are You Ready: Financial Management, Operating Reserves, and the Immediate Impact of COVID-19 on Nonprofits. Nonprofit and Voluntary Sector Quarterly, 49(6), 1191-1209

Krawczyk, K. (2018). The relationship between Liberian CSOs and international donor funding: Boon or bane? VOLUNTAS: International Journal of Voluntary and Nonprofit Organisations, 29(2), 296-309.

Kumi, E. (2017). Diversify or Die? The Response of Ghanaian Non-Governmental Development Organisations (NGDOs) to a Changing Aid Landscape. PhD Thesis, University of Bath, United Kingdom.

Kumi, E. (2019). Aid Reduction and NGDOs' Quest for Sustainability in Ghana: Can Philanthropic Institutions Serve as Alternative Resource Mobilisation Routes?. Voluntas: International Journal of Voluntary and Nonprofit Organisations, 30(6), 1332-1347

Miao, Q., Schwarz, S., \& Schwarz, G. (2021). Responding to COVID-19: Community volunteerism and coproduction in China. World development, 137, 105128.

Nganji, J. T., \& Cockburn, L. (2020). Use of Twitter in the Cameroon Anglophone crisis. Behaviour \& Information Technology, 39(3), 267-287.

Olawoore, B. (2017). The implications of the rights-based approach on NGOs' funding.

Development in Practice, 27(4), 515-527. 


\section{References}

Pandya, A., \& Ron, J. (2017). Local resources for local rights? The Mumbai '" 'fundraiser's dilemma. Journal of Human Rights, 16(3), 370-387.

Pousadela, I. M., \& Cruz, A. (2016). The sustainability of Latin American CSOs: Historical patterns and new funding sources. Development in Practice, 26(5), 606-618.

Sloan, M. F., Charles, C., \& Kim, M. (2016). Nonprofit leader perceptions of operating reserves and their substitutes. Nonprofit Management and Leadership, 26(4), 417-433

TUSEV (2020). The impact of covid-19 outbreak on civil society organisations operating in Turkey. Retrieved from:

https://www.efc.be/news-post/tusev-publish-the-impact-of-covid-19-outbreak-on-civil-society-or ganizations-operating-in-turkey-survey-ii-report-in-english/

Vandyck, C. K. (2020c). COVID-19 reveals local fundraising capacity as civil society's weakest link in West Africa. Blog post. Retrieved from: https://www.wacsi.org/blog/blog_detail.php?id=41 
